\title{
Riociguat for interstitial lung disease and pulmonary hypertension: a pilot trial
}

\author{
Marius M. Hoeper*, Michael Halank* , Heinrike Wilkens ${ }^{\star}$, Andreas Günther ${ }^{+}$, \\ Gerrit Weimann ${ }^{\S}$, Irmingard Gebert ${ }^{\dagger}$, Hanno H. Leuchte** and Jürgen Behr ${ }^{\star \#}$
}

\begin{abstract}
We assessed the safety, tolerability and preliminary efficacy of riociguat, a soluble guanylate cyclase stimulator, in patients with pulmonary hypertension associated with interstitial lung disease (PH-ILD).
\end{abstract}

In this open-label, uncontrolled pilot trial, patients received oral riociguat (1.0-2.5 $\mathrm{mg}$ three times daily) for 12 weeks $(n=22)$, followed by an ongoing long-term extension (interim analysis at 12 months) in those eligible $(n=15)$. Primary end-points were safety and tolerability. Secondary end-points included haemodynamic changes and 6-min walk distance (6MWD).

Overall, 104 adverse events were reported, of which 25 were serious; eight of the latter were considered drug-related. After 12 weeks of therapy, mean cardiac output increased $\left(4.4 \pm 1.5 \mathrm{~L} \cdot \mathrm{min}^{-1}\right.$ to $\left.5.5 \pm 1.8 \mathrm{~L} \cdot \mathrm{min}^{-1}\right)$, pulmonary vascular resistance (PVR) decreased $\left(648 \pm 207 \mathrm{dyn} \cdot \mathrm{s}^{-1} \cdot \mathrm{cm}^{-5}\right.$ to $528 \pm 181 \mathrm{dyn} \cdot \mathrm{s}^{-1} \cdot \mathrm{cm}^{-5}$ ) and mean pulmonary artery pressure (mPAP) remained unchanged compared with baseline. Arterial oxygen saturation decreased but mixed-venous oxygen saturation slightly increased. The 6MWD increased from $325 \pm 96 \mathrm{~m}$ at baseline to $351 \pm 111 \mathrm{~m}$ after 12 weeks.

Riociguat was well tolerated by most patients and improved cardiac output and PVR, but not mPAP. Further studies are necessary to evaluate the safety and efficacy of riociguat in patients with PH-ILD.

KEYWORDS: Clinical study, interstitial lung disease, pulmonary hypertension, riociguat, soluble guanylate cyclase

I nterstitial lung disease (ILD) represents a heterogeneous group of diseases that share common functional features including a decline in pulmonary compliance and impairment of gas exchange [1-3]. The underlying pathology of ILD is characterised by fibrous remodelling of the pulmonary interstitium which ultimately results in irreversible structural changes and death. There are still no effective therapies for many forms of ILD.

Approximately $30-40 \%$ of patients with ILD develop pulmonary hypertension $(\mathrm{PH})$, which contributes significantly to their functional impairment and substantially worsens their prognosis [1, 4-8]. Thus, there is a growing interest in targeting $\mathrm{PH}$ in patients with ILD.

Various classes of drugs, including endothelin receptor antagonists, prostanoids and phosphodiesterase-5 (PDE-5) inhibitors [9-11], have beneficial effects in patients with pulmonary arterial hypertension (PAH). Case reports and open-label studies have suggested that some of these drugs might also improve haemodynamics and exercise capacity in patients with PH-ILD [12-15]. A recent placebo-controlled 12-week study of the PDE-5 inhibitor sildenafil in patients with advanced idiopathic pulmonary fibrosis (IPF) failed to show a significant change in 6-min walk distance (6MWD), although there were beneficial effects on arterial blood gases and carbon monoxide diffusion capacity and health-related quality of life measures [16]. No randomised controlled trials of PAH treatments in the PH-ILD patient population have been published. Consequently, no pharmacological therapy has gained regulatory approval for the specific indication of PH-ILD, and due to the lack of robust data, current $\mathrm{PH}$ guidelines discourage the off-label use of PAH-targeting drugs in such patients $[3,17]$. Conventional vasodilators are also not recommended in $\mathrm{PH}-$ ILD because they may impair gas exchange due to the inhibition of hypoxic pulmonary vasoconstriction [17]. Therefore, the enrolment of patients in high-quality clinical trials in order to identify new therapeutic options is vital [18].

\section{AFFILIATIONS}

*Dept of Respiratory Medicine,

Hannover Medical School, Hannover

"Dept of Internal Medicine I,

University Hospital Carl Gustav Carus, Dresden,

-Dept of Internal Medicine II,

University of the Saarland, Homburg,

${ }^{+}$Dept of Internal Medicine, Giessen

University, Giessen,

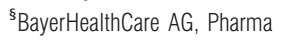

Research Centre, Wuppertal,

${ }^{f}$ Bayer HealthCare, Bayer Vital GmbH, Pharma Medical Dept, Leverkusen,

${ }^{* *}$ Dept of Internal Medicine I,

Grosshadern Clinic, Ludwig

Maximilian University of Munich,

Munich, and

\#\#\# Dept of Internal Medicine II. University Hospital Bergmannsheil, Bochum, Germany.

CORRESPONDENCE

M.M. Hoeper

Dept of Respiratory Medicine

Hannover Medical School

30623 Hannover

Germany

E-mail: hoeper.marius@mh-

hannover.de

Received:

Dec 062011

Accepted after revision:

July 202012

First published online:

Aug 302012 
The development of new classes of drugs for the treatment of $\mathrm{PH}$ depends on improved understanding of its pathophysiology. In healthy individuals, endothelial cell-derived nitric oxide (NO) acts on smooth muscle cells to induce vasodilation by increasing production of the second messenger cyclic guanosine monophosphate (cGMP) via activation of the intracellular enzyme soluble guanylate cyclase (sGC) $[19,20]$. In $\mathrm{PH}$, production of $\mathrm{NO}$ is reduced, resulting in inhibition of sGC activity and depletion of cGMP which can lead to numerous abnormalities including pulmonary vasoconstriction, adverse vascular remodelling and in situ thrombosis [21, 22]. Riociguat is the first of a new class of drugs, the sGC stimulators, designed to both stimulate sGC independently of $\mathrm{NO}$ and sensitise the enzyme to low levels of NO, thereby restoring cGMP levels [23]. As a result of its NO-independent action, riociguat could be effective under conditions of $\mathrm{NO}$ depletion that restrict the effectiveness of PDE-5 inhibitors.

In a preliminary, non-controlled study in patients with $\mathrm{PAH}$ and chronic thromboembolic pulmonary hypertension (CTEPH), riociguat improved exercise capacity, functional class and pulmonary haemodynamics [24]. Furthermore, in an acute haemodynamic study that included some patients with PH-ILD, riociguat improved haemodynamics without worsening gas exchange [25]. Based on these observations we hypothesised that riociguat could have beneficial effects in patients with PH-ILD. In this pilot trial we primarily assessed safety and tolerability of riociguat in this patient population and studied preliminary effects of the drug on haemodynamics, blood gases and exercise capacity.

\section{METHODS}

\section{Study design and patients}

This multicentre, open-label, non-blinded, non-randomised, uncontrolled phase II study was conducted across five centres in Germany. Patients aged $\geqslant 18$ years diagnosed with any of four types of ILD (IPF, non-specific interstitial lung disease (NSILD), scleroderma or sarcoidosis) and a total lung capacity (TLC) $\leqslant 90 \%$ of the predicted value $(\leqslant 80 \%$ of the predicted value in patients with scleroderma) were enrolled. Eligible patients also had a mean pulmonary artery pressure (mPAP) $>30 \mathrm{mmHg}$, a pulmonary capillary wedge pressure (PCWP) $<15 \mathrm{mmHg}$ and a pulmonary vascular resistance (PVR) $>400 \mathrm{dyn} \cdot \mathrm{s}^{-1} \cdot \mathrm{cm}^{-5}$, as demonstrated by right heart catheterisation within 3 months prior to the commencement of the study. For at least 3 months before study entry, patients were required to have stable ILD (decrease in forced expiratory volume in one second (FEV1) $<10 \%$ and decrease in diffusing capacity of lung for carbon monoxide $<15 \%$ ) and be on stable medication (e.g. no changes in the doses of corticosteroids and/ or immunosuppressants, if present, during that time).

The most important exclusion criteria were previous or ongoing treatments with other $\mathrm{PH}$ - or $\mathrm{PAH}$-targeting drugs, including prostanoids, endothelin receptor antagonists or PDE-5 inhibitors. The use of nitrates was also prohibited. Further exclusion criteria included: advanced pulmonary fibrosis indicated by a TLC $\leqslant 30 \%$ pred; an arterial oxygen tension $\left(\mathrm{PaO}_{2}\right)<50 \mathrm{mmHg}$ or an arterial carbon dioxide tension $\left(\mathrm{PaCO}_{2}\right)>45 \mathrm{mmHg}$ in room air; other clinically relevant lung diseases including more than mild airflow obstruction (FEV1 to forced vital capacity ratio $\leqslant 60 \%$ ); severe congenital abnormalities of the lungs, thorax or diaphragm; left ventricular dysfunction (left ventricular ejection fraction $<50 \%$ ); and symptomatic coronary heart disease.

The study was performed in accordance with the Good Clinical Practice guidelines and the guiding principles detailed in the Declaration of Helsinki. The study protocol was approved by the ethics committees of all participating centres and all patients gave their written informed consent.

\section{Procedures}

Riociguat (Bayer HealthCare AG, Wuppertal, Germany) was administered orally three times daily for 12 weeks, titrated in $0.5 \mathrm{mg}$ increments at 2-week intervals from a starting dose of $1 \mathrm{mg}$ to a target dose of $2.5 \mathrm{mg}$ three times daily. Systolic blood pressure (SBP) was measured in resting patients $1 \mathrm{~h}$ before administration of the morning dose of riociguat. The dose was increased if SBP was $>100 \mathrm{mmHg}$, maintained if SBP was 90$100 \mathrm{mmHg}$ and reduced if SBP was $<90 \mathrm{mmHg}$ without symptoms of hypotension (such as dizziness or syncope). Riociguat was stopped if SBP was $<90 \mathrm{mmHg}$ with clinical signs of hypotension. Re-start of treatment was possible after $24 \mathrm{~h}$ at a reduced dose (-0.5 $\mathrm{mg}$ three times daily). Riociguat was discontinued permanently if the resting heart rate increased above 120 beats per minute (bpm) or if SBP fell below $80 \mathrm{mmHg}$. Patients who tolerated treatment well were enrolled in an ongoing long-term extension study. Interim analysis at 12 months of this ongoing study is presented here.

As this was essentially a safety study, the primary end-points were safety and tolerability throughout the initial 12-week study period and at 12 months. Vital signs, ECG findings and laboratory parameters were evaluated every 2 weeks during the initial treatment period and every 3 months thereafter. Laboratory parameters included blood gases, haematology, clinical chemistry including N-terminal pro-brain natriuretic peptide (NT-proBNP) and urine composition.

The major efficacy outcomes at 12 weeks were the $6 \mathrm{MWD}$, the modified Borg dyspnoea score (at the end of the 6MWD), functional class and quality of life scores (SF-36 and EuroQoL). Patients were allowed to use oxygen during all study procedures, including the 6-min walk test, but they were required to maintain the same flow of oxygen throughout the study. Mixed-venous oxygen saturation ( $\mathrm{SvO}_{\mathrm{V}}$ ) and haemodynamic parameters including right atrial pressure, $\mathrm{mPAP}$ and PCWP were measured during right heart catheterisation at baseline and week 12. Arterial oxygen saturation was measured by pulse oximetry $\left(\mathrm{SpO}_{2}\right)$, cardiac output was measured by thermodilution and systemic arterial pressure was measured non-invasively. Systemic vascular resistance (SVR), PVR and cardiac index were calculated by standard formulae. 6MWD was the only efficacy outcome assessed during the long-term extension period.

\section{Statistical methods}

Statistical analyses undertaken in this small open-label, uncontrolled pilot trial were largely descriptive, and there was no formal statistical sample size estimation. Safety analyses were based on those patients who received at least one dose of study medication. At the end of the 12-week study period, 95\% confidence intervals were calculated for changes in efficacy parameters from baseline. Efficacy analyses were 
performed only in patients who completed the study (perprotocol population). No imputations have been made. Efficacy results were expressed descriptively for the extension study. Results are given as mean \pm SD unless stated otherwise.

\section{RESULTS}

\section{Patient demographics and drug dosing}

A total of 23 patients were enrolled in this study, 22 of whom received at least one dose of riociguat and were valid for safety or intention to treat analysis (fig. 1). Of these 22 patients, their mean age was 60.5 years (range 33.0-80.0 years), mean body mass index was $26 \pm 4 \mathrm{~kg} \cdot \mathrm{m}^{-2}, 14$ were males $(63.6 \%)$ and all were Caucasian (table 1). Concomitant medications were being used by all patients, the most common of which were corticosteroids $(81.8 \%)$ and proton-pump inhibitors (59.1\%). Of the 22 patients receiving the study drug, all had $\mathrm{PH}: 13$ (59.1\%) had a diagnosis of IPF-associated PH; five (22.7\%) had NSILD-associated PH; three $(13.6 \%)$ had sarcoidosis-associated $\mathrm{PH}$; and one $(4.5 \%)$ had scleroderma-associated interstitial lung disease and $\mathrm{PH}$.

At the end of the 12-week study, 14 (63.6\%) patients were receiving riociguat $2.5 \mathrm{mg}$ three times daily, three patients were treated with $2.0 \mathrm{mg}$ three times daily and one received $1.5 \mathrm{mg}$ three times daily The final total daily doses of riociguat for all patients, including those who discontinued during the

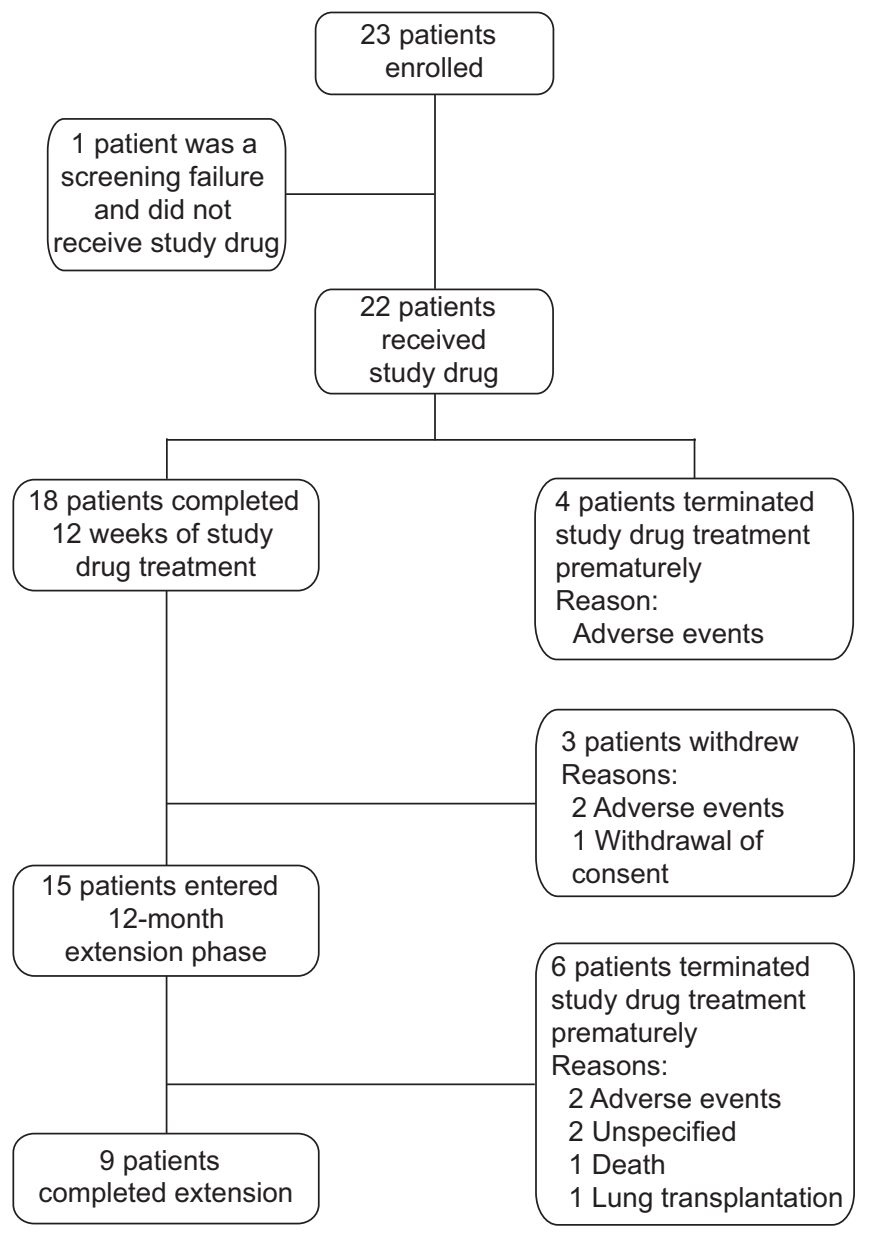

FIGURE 1. Study design and patient flow (at 12 month interim analysis). first 12 weeks and those who continued into the 12-month extension, were $0.5 \mathrm{mg}$ three times daily in one patient, $1.0 \mathrm{mg}$ three times daily in two patients, $1.5 \mathrm{mg}$ three times daily in two patients, $2.0 \mathrm{mg}$ three times daily in four patients and $2.5 \mathrm{mg}$ three times daily in 13 patients.

\section{Safety}

Discontinuations

In the initial 12-week phase, four patients discontinued therapy permanently due to adverse events: leg oedema, relapsing syncope, intense gastroenteritis/leg oedema and progression of ILD. Two of these withdrawals were considered related to the study drug (syncope and intense gastroenteritis/ leg oedema, respectively). 18 patients completed 12 weeks of treatment and 15 entered the long-term extension phase. During the long-term extension, a further six patients discontinued therapy permanently: one patient died from disease progression and respiratory failure; one patient underwent lung transplantation; two withdrew due to adverse

\begin{tabular}{|c|c|c|}
\hline TABLE 1 & \multicolumn{2}{|c|}{$\begin{array}{l}\text { Baseline demographics and clinical } \\
\text { characteristics of the patients }\end{array}$} \\
\hline Patients n & & 22 \\
\hline Age years & & $60.5(33.0-80.0)$ \\
\hline White ethnic & & $22(100.0)$ \\
\hline Male sex & & $14(63.6)$ \\
\hline$B M I \mathbf{k g} \cdot \mathbf{m}^{-2}$ & & $26 \pm 4$ \\
\hline \multicolumn{3}{|c|}{ WHO functional class } \\
\hline III & & $19(86.4)$ \\
\hline IV & & $3(13.6)$ \\
\hline 6-min walk c & istance $\mathrm{m}$ & $316 \pm 96$ \\
\hline \multicolumn{3}{|c|}{ Underlying disease } \\
\hline Idiopathic & ulmonary fibrosis & $13(59.1)$ \\
\hline Non-specif & interstitial lung disease & $5(22.7)$ \\
\hline Sarcoidosis & & $3(13.6)$ \\
\hline Systemic s & lerosis & $1(4.5)$ \\
\hline \multicolumn{3}{|c|}{ Pulmonary function } \\
\hline TLC \% pres & & $67 \pm 12$ \\
\hline FVC \% pre & & $67 \pm 20$ \\
\hline FEV $1 \%$ pre & & $67 \pm 17$ \\
\hline$D \mathrm{LCO}^{\#} \mathrm{~mm}$ & $\mathrm{l} \cdot \mathrm{min}^{-1} \cdot \mathrm{kPa}^{-1}$ & $2.7 \pm 1.5$ \\
\hline \multicolumn{3}{|c|}{ Haemodynamics and blood gases } \\
\hline Mean pulm & nary artery pressure $\mathrm{mmHg}$ & $40 \pm 10$ \\
\hline Pulmonary & /ascular resistance dyn $\cdot \mathrm{s}^{-1} \cdot \mathrm{cm}^{-5}$ & $656 \pm 201$ \\
\hline Cardiac ou & put $L \cdot \min ^{-1}$ & $4.3 \pm 1.4$ \\
\hline Systolic blc & od pressure ${ }^{\#} \mathrm{mmHg}$ & $136 \pm 16$ \\
\hline Heart rate" & beats per minute & $78 \pm 14$ \\
\hline $\mathrm{SPO}_{2} \%$ & & $94 \pm 3$ \\
\hline $\mathrm{SvO}_{2}{ }^{\circ} \%$ & & $62 \pm 12$ \\
\hline $\mathrm{PaCO}_{2} \mathrm{mml}$ & & $39 \pm 7$ \\
\hline \multicolumn{3}{|c|}{$\begin{array}{l}\text { Data are presented as mean (range), } \mathrm{n}(\%) \text { or mean } \pm \mathrm{SD} \text {, unless otherwise } \\
\text { stated. BMI: body mass index; WHO: World Health Organization; TLC: total } \\
\text { lung capacity; \% pred: \% predicted; FVC: forced vital capacity; FEV1: forced } \\
\text { expiratory volume in } 1 \mathrm{~s} \text {; DLCO: diffusing capacity of lung for carbon monoxide; } \\
\mathrm{SPO}_{2} \text { : arterial oxygen saturation measured by pulse oximetry; } \mathrm{SvO}_{2} \text { : mixed- } \\
\text { venous oxygen saturation; PaCO}: \text { arterial carbon dioxide tension. " }{ }^{\#} \text { : data } \\
\text { available for } 20 \text { patients. " } \text { data available for } 21 \text { patients. }\end{array}$} \\
\hline
\end{tabular}




\begin{tabular}{|c|c|c|c|}
\hline $\begin{array}{ll}\text { TABLE } 2 & \text { Treatment-emergent and } d \\
\text { treatment or continuation } p\end{array}$ & $\begin{array}{l}\text { related adverse event } \\
\text { es of the study }\end{array}$ & oerienced by two or more & nts during the 12 -week \\
\hline Adverse events & $\begin{array}{l}\text { Adverse event in two or } \\
\text { more patients }\end{array}$ & Treatment-emergent events & $\begin{array}{c}\text { Drug-related treatment-emergent } \\
\text { events }\end{array}$ \\
\hline Oedema peripheral & $8(36.4)$ & $8(36.4)$ & $6(27.3)$ \\
\hline Dyspnoea & $7(31.8)$ & $7(31.8)$ & $6(27.3)$ \\
\hline Dyspepsia & $5(22.7)$ & $5(22.7)$ & $3(13.6)$ \\
\hline Nasopharyngitis & $5(22.7)$ & $5(22.7)$ & $0(0)$ \\
\hline Headache & $4(18.2)$ & $4(18.2)$ & $3(13.6)$ \\
\hline Feeling hot & $3(13.6)$ & $3(13.6)$ & $3(13.6)$ \\
\hline Bronchitis & $3(13.6)$ & $3(13.6)$ & $0(0)$ \\
\hline Pancytopenia & $2(9.1)$ & $2(9.1)$ & $2(9.1)$ \\
\hline Gastroenteritis & $2(9.1)$ & $2(9.1)$ & $1(4.5)$ \\
\hline Hypoxaemia & $2(9.1)$ & $2(9.1)$ & $2(9.1)$ \\
\hline Hypotension & $2(9.1)$ & $2(9.1)$ & $1(4.5)$ \\
\hline Respiratory failure & $2(9.1)$ & $2(9.1)$ & $1(4.5)$ \\
\hline Right ventricular failure & $2(9.1)$ & $2(9.1)$ & $1(4.5)$ \\
\hline Respiratory tract infection & $2(9.1)$ & $2(9.1)$ & $0(0)$ \\
\hline Pulmonary fibrosis & $2(9.1)$ & $1(4.5)$ & $0(0)$ \\
\hline Diarrhoea & $2(9.1)$ & $2(9.1)$ & $0(0)$ \\
\hline Total number of patients reporting any event & $21(95.5)$ & $20(90.9)$ & $15(68.2)$ \\
\hline
\end{tabular}

Data are presented as $n(\%)$.

events (increasing dyspnoea, leg oedema); and two for unspecified reasons. The case of increasing dyspnoea was considered to be potentially related to study medication by both the investigator and the sponsor. The patient in question had IPF-associated PH and it could not be determined whether the clinical worsening was due to disease progression or due to study medication. The patient who underwent lung transplantation died shortly after the procedure (9 days after transplantation and 17 days after discontinuation of riociguat). No other patient underwent lung transplantation during the study period. Both deaths were considered unrelated to riociguat by the investigators and the sponsor.

Hypotension was observed in two patients (9.1\%): no case of hypotension led to permanent discontinuation of riociguat. One additional patient had an episode of syncope, which led to permanent discontinuation of the study drug after completion of the 12-week main phase of the study.

\section{Adverse events}

Overall, 104 adverse events were reported across the 22 patients during the 12-week treatment period and the extension phase combined. Of these, 86 were considered treatmentemergent (all events post-baseline assessment) and approximately $70 \%$ were considered drug-related. Table 2 shows the adverse events reported by two or more patients (approximately $10 \%$ of the population). The most frequently reported drug-related adverse events were dyspnoea ( $n=6,27.3 \%)$, peripheral oedema $(n=6,27.3 \%)$, dyspepsia $(n=3,13.6 \%)$, headache $(n=3,13.6 \%)$ and feeling hot $(n=3,13.6 \%)$.

\section{Serious adverse events}

Overall, 16 patients experienced 25 serious adverse events. These included dyspnoea $(n=4)$, pancytopenia $(n=2)$, right ventricular failure, chest pain, bronchitis, diverticulitis, hyponatraemia, hypokalaemia, peripheral oedema, syncope $(n=2)$, progression of ILD, progressive massive fibrosis, pulmonary fibrosis $(n=2)$, viral-triggered exacerbation of lung fibrosis, respiratory disorder, coronary artery disease, closed perforation of a gastric ulcer and respiratory failure $(n=2)$. A total of eight serious adverse events were considered possibly related to the study drug: syncope $(n=1)$; dyspnoea $(n=3)$; pancytopenia $(n=2)$; respiratory disorder $(n=1)$; and respiratory failure $(n=1)$.

\section{Laboratory parameters and QT time}

Changes in laboratory parameters including haematology, clinical chemistry, and urine composition were infrequent and none gave any indication of being related to the study medication (data not shown). Serum NT-proBNP did not change from baseline $\left(1061.6 \pm 1511.9 \mathrm{pg} \cdot \mathrm{mL}^{-1}\right.$ at baseline $(\mathrm{n}=19)$ versus $1227.6 \pm 1352.0 \mathrm{pg} \cdot \mathrm{mL}^{-1}(\mathrm{n}=16)$ at week 12$)$. No untoward effects on corrected QT interval duration were evident during the study.

\section{Haemodynamics}

Haemodynamic results are described below as mean \pm SD for patients with an assessment at baseline and at least once thereafter $(n=15)$. Individual patient data for cardiac output, PVR and mPAP are shown in figure 2.

Compared with baseline, cardiac output increased from $4.4 \pm 1.5 \mathrm{~L} \cdot \mathrm{min}^{-1}$ to $5.5 \pm 1.8 \mathrm{~L} \cdot \mathrm{min}^{-1}$ (difference: $+1.2 \pm 1.0 \mathrm{~L} \cdot \mathrm{min}^{-1}$, 95\% CI 0.6-1.8 L. $\mathrm{min}^{-1}$ ) and cardiac index from $2.4 \pm 0.8 \mathrm{~L}$. $\mathrm{min}^{-1} \cdot \mathrm{m}^{-2}$ to $3.0 \pm 1.1 \mathrm{~L} \cdot \mathrm{min}^{-1} \cdot \mathrm{m}^{-2}$ (difference: $+0.7 \pm 0.7 \mathrm{~L} \cdot \mathrm{min}^{-1}$. $\left.\mathrm{m}^{-2}, 95 \% \mathrm{CI} 0.3-1.0 \mathrm{~L} \cdot \mathrm{min}^{-1} \cdot \mathrm{m}^{-2}\right)$ at week 12 . Heart rate increased 

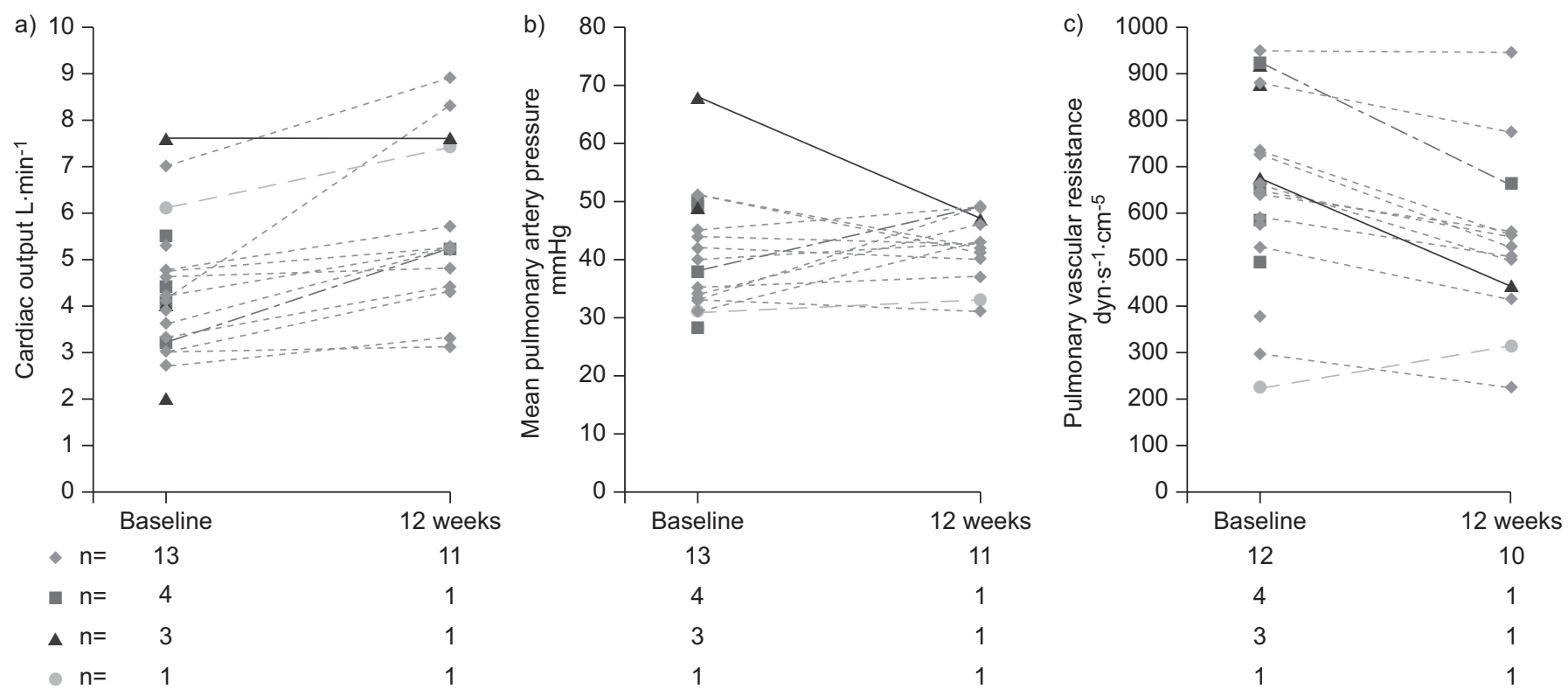

FIGURE 2. a) Cardiac output, b) mean pulmonary artery pressure and c) pulmonary vascular resistance at baseline and after 12 weeks of treatment with riociguat (0.5-2.5 mg three times daily). Data are shown for each individual patient, with diagnosis of idiopathic pulmonary fibrosis-associated pulmonary hypertension (PH) (diamonds), non-specific interstitial lung disease-associated PH (squares), sarcoidosis-associated PH (triangles) or scleroderma-associated interstitial lung disease and PH (circles), also indicated.

from $79 \pm 14 \mathrm{bpm}$ at baseline to $86 \pm 16 \mathrm{bpm}$ at week 12 (difference: $+7 \pm 12 \mathrm{bpm}, 95 \%$ CI 1-14 bpm).

Between baseline and week 12 (in those patients who had at least one post-baseline assessment), PVR decreased from $648 \pm 207 \mathrm{dyn} \cdot \mathrm{s}^{-1} \cdot \mathrm{cm}^{-5}$ to $528 \pm 181 \mathrm{dyn} \cdot \mathrm{s}^{-1} \cdot \mathrm{cm}^{-5}$ (difference: $-120 \pm 93 \mathrm{dyn} \cdot \mathrm{s}^{-1} \cdot \mathrm{cm}^{-5}, 95 \%$ CI $\left.-174--66 \mathrm{dyn} \cdot \mathrm{s}^{-1} \cdot \mathrm{cm}^{-5}\right)$ and SVR from $2057 \pm 808 \mathrm{dyn} \cdot \mathrm{s}^{-1} \cdot \mathrm{cm}^{-5}$ to $1324 \pm 278 \mathrm{dyn} \cdot \mathrm{s}^{-1} \cdot \mathrm{cm}^{-5}$ (difference: $-821 \pm 607 \mathrm{dyn} \cdot \mathrm{s}^{-1} \cdot \mathrm{cm}^{-5}, 95 \%$ CI $\left.-1787-145 \mathrm{dyn} \cdot \mathrm{s}^{-1} \cdot \mathrm{cm}^{-5}\right)$. This resulted in an increase in the PVR/SVR ratio from 0.31 at baseline to 0.40 after 12 weeks. MPAP was virtually unchanged $(40 \pm 10 \mathrm{mmHg}$ at baseline versus $41 \pm 7 \mathrm{mmHg}$ at week 12; difference: $+1 \pm 10 \mathrm{mmHg}$, 95\% CI $-5-6 \mathrm{mmHg}$ ). SBP fell from
$139 \pm 14 \mathrm{mmHg}$ to $130 \pm 16 \mathrm{mmHg}$ (difference: $-9.3 \pm 19.2 \mathrm{mmHg}$, 95\% CI -19.93-1.33 mmHg).

\section{Blood gases}

The full data set from haemodynamic measurements and blood gas analyses is shown in table $3 . \mathrm{PaO}_{2}$ decreased by $7 \pm 12 \mathrm{mmHg}(95 \% \mathrm{CI}-13--1 \mathrm{mmHg})$ at 12 weeks and by $3 \pm 12 \mathrm{mmHg}$ at 12 months. $\mathrm{PaCO}_{2}$ decreased by $3 \pm 2 \mathrm{mmHg}(95 \%$ $\mathrm{CI}-4--2 \mathrm{mmHg}$ ) at 12 weeks and increased by $1 \pm 2 \mathrm{mmHg}$ at 12 months (fig. 3). $\mathrm{SvO}_{2}$ showed a slight improvement between baseline and week 12 ( $65 \pm 6 \%$ to $67 \pm 7 \%$; difference: $+2 \pm 4 \%$, $95 \%$ CI $0-4 \%)$.

TABLE 3 Change from baseline in haemodynamic and blood gas parameters following the 12-week treatment and continuation phase of the study

\begin{tabular}{|c|c|c|c|c|c|c|c|}
\hline \multirow[t]{2}{*}{ Parameter } & \multicolumn{2}{|c|}{ Baseline } & \multicolumn{3}{|c|}{12 weeks } & \multicolumn{2}{|c|}{12 months } \\
\hline & $\mathbf{n}$ & Mean \pm SD & $\mathbf{n}$ & Difference $\pm S D$ & $95 \% \mathrm{Cl}$ & $\mathbf{n}$ & Difference $\pm S D$ \\
\hline Cardiac output $L \cdot \mathrm{min}^{-1}$ & 15 & $4.4 \pm 1.5$ & 15 & $+1.2 \pm 1.0$ & $0.6-1.8$ & & \\
\hline Cardiac index $L \cdot \mathrm{min}^{-1} \cdot \mathrm{m}^{-2}$ & 15 & $2.4 \pm 0.8$ & 15 & $+0.7 \pm 0.7$ & $0.3-1.0$ & & \\
\hline Pulmonary vascular resistance $\mathrm{dyn} \cdot \mathrm{s}^{-1} \cdot \mathrm{cm}^{-5}$ & 14 & $648 \pm 207$ & 14 & $-120 \pm 93$ & $-174--66$ & & \\
\hline Mean pulmonary artery pressure $\mathrm{mmHg}$ & 15 & $40 \pm 10$ & 15 & $+1 \pm 10$ & $-5-6$ & & \\
\hline Pulmonary capillary wedge pressure $\mathrm{mmHg}$ & 14 & $7 \pm 5$ & 14 & $+1 \pm 5$ & $-2-4$ & & \\
\hline Systemic vascular resistance dyn $\cdot \mathrm{s}^{-1} \cdot \mathrm{cm}^{-5}$ & 8 & $2057 \pm 808$ & 4 & $-821 \pm 607$ & $-1787-145$ & & \\
\hline Heart rate beats per minute & 15 & $79 \pm 14$ & 15 & $+7 \pm 12$ & $1-14$ & & \\
\hline $\mathrm{SvO}_{2} \%$ & 15 & $65 \pm 6$ & 15 & $+2 \pm 4$ & $0-4$ & & \\
\hline $\mathrm{SPO}_{2}{ }^{\#} \%$ & 22 & $94 \pm 3$ & 17 & $-1 \pm 5$ & $-4-1$ & 8 & $0 \pm 2$ \\
\hline $\mathrm{PaO}_{2}$ (capillary) $\mathrm{mmHg}$ & 19 & $69 \pm 14$ & 16 & $-7 \pm 12$ & $-13--1$ & 8 & $-3 \pm 12$ \\
\hline $\mathrm{PaCO}_{2}$ (capillary) $\mathrm{mmHg}$ & 19 & $38 \pm 7$ & 16 & $-3 \pm 2$ & $-4--2$ & 8 & $+1 \pm 2$ \\
\hline
\end{tabular}

$\mathrm{SvO}_{2}$ : mixed-venous oxygen saturation; $\mathrm{SPO}_{2}$ : arterial oxygen saturation measured by pulse oximetry; $\mathrm{PaO}_{2}$ : arterial oxygen tension; $\mathrm{PaCO}$ : arterial carbon dioxide tension

\# : measured by pulse oximetry. 

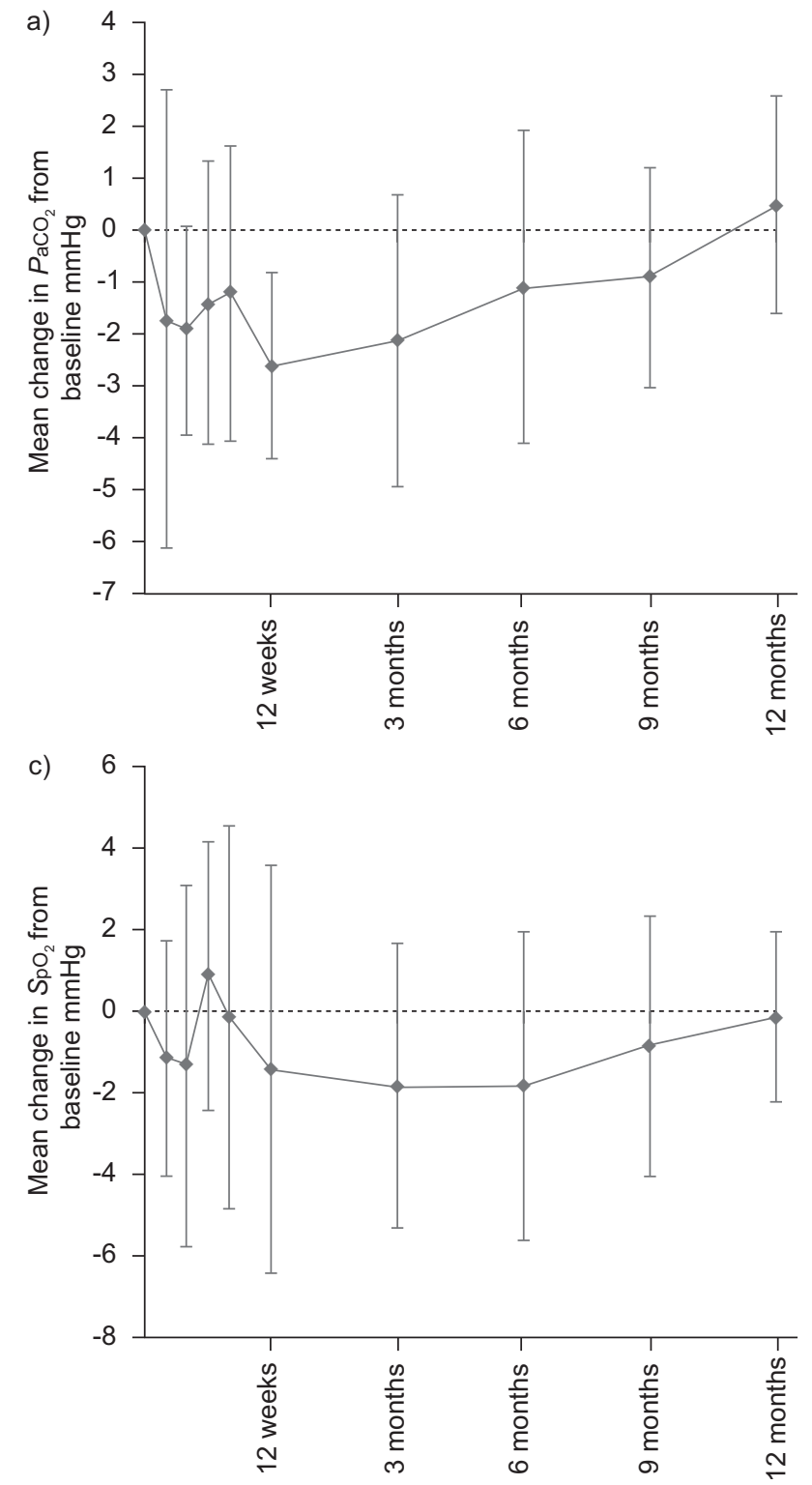

\section{Pulse oximetry}

$\mathrm{SaO}_{2}$ was measured by pulse oximetry. $\mathrm{SaO}_{2}$ decreased by $1 \pm 5 \%(95 \% \mathrm{CI}-4-1 \%)$ at 12 weeks and $0 \pm 2 \%$ at 12 months from a baseline value of $93.7 \pm 3.1 \%$.

\section{Functional class, exercise capacity and quality of life}

The 6MWD increased slightly to $351 \pm 111 \mathrm{~m}$ after 12 weeks, from a corresponding baseline of $325 \pm 96 \mathrm{~m}(\mathrm{n}=17)$ (difference: $+25 \pm 64 \mathrm{~m}, 95 \% \mathrm{CI}-8-58 \mathrm{~m}$ ). As shown in figure 4 , most patients experienced further improvements in 6MWD during follow-up. A single patient was removed from the analysis at 12 weeks as the $6 \mathrm{MWD}$ could not be conducted properly.

Mean changes in modified Borg scores ranged from -0.2 to +0.5 during the initial 12-week trial. The descriptive statistics of the modified Borg score showed no relevant change compared with baseline overall (data not shown).

At baseline, 19 patients were in World Health Organization functional class III and three were in functional class IV. In 16

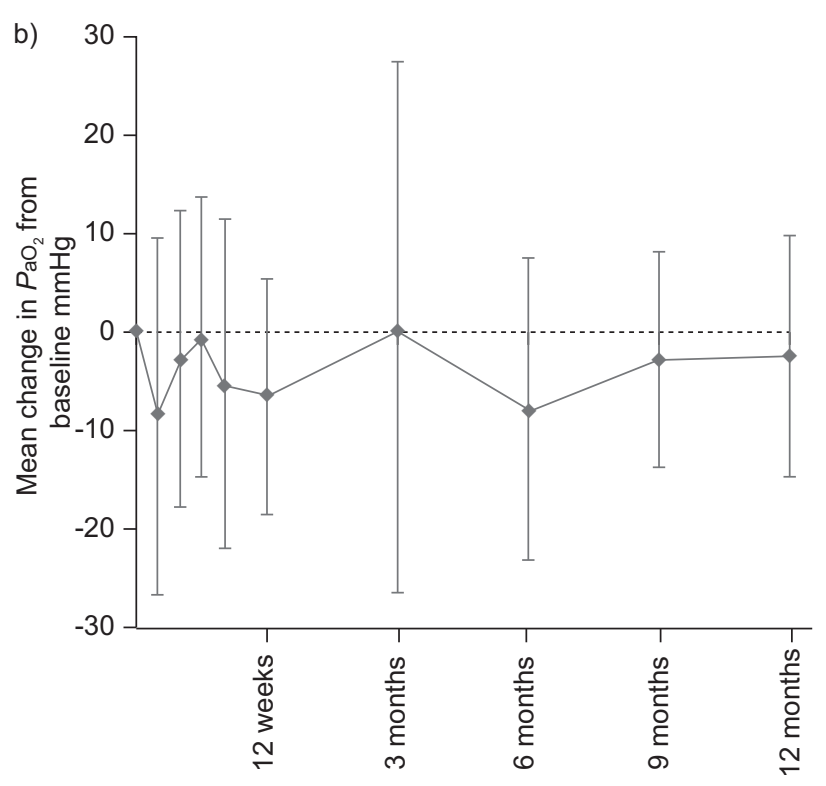

FIGURE 3. Mean $\pm \mathrm{SD}$ change from baseline in a) arterial carbon dioxide tension $\left(\mathrm{PaCO}_{2}\right)$, b) arterial oxygen tension $\left(\mathrm{PaO}_{2}\right)$ and c) arterial oxygen saturation measured by pulse oximetry $\left(\mathrm{SpO}_{2}\right)$ after treatment with riociguat (0.5-2.5 mg three times daily).

of the 18 patients available at week 12 functional class remained unchanged. One patient had improved to functional class II and one patient had worsened to functional class IV.

At 12 weeks the overall EuroQol EQ-5D scores showed no relevant changes compared with baseline. In most patients (58.8-82.4\%), the individual scores (for mobility, self-care, usual activities, pain/discomfort or anxiety/depression) remained unchanged and fewer than $30 \%$ of patients showed an improvement or worsening in any score.

The SF-36 scale assessment did not indicate relevant changes between baseline and week 12 .

\section{DISCUSSION}

The primary objective of the current pilot study was to assess the safety and tolerability of riociguat in patients with PH-ILD. Riociguat was well tolerated by most patients with the incidence and nature of adverse events generally similar to previous clinical studies of the drug [24, 25]. Only two patients 


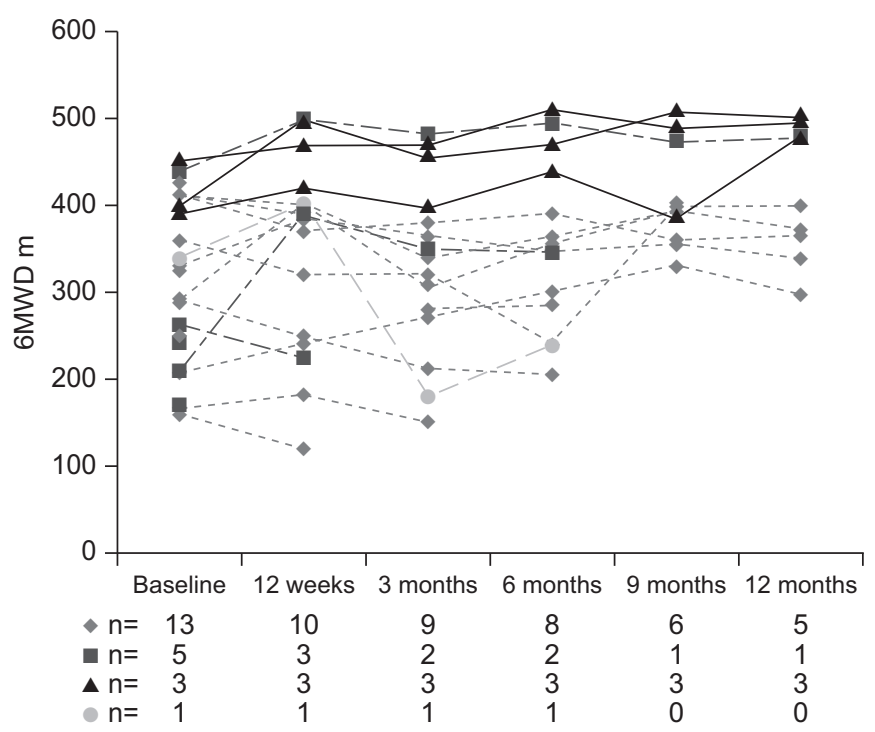

FIGURE 4. 6-min walk distance (6MWD) during the 12-week main study and extension study of treatment with riociguat $(0.5-2.5 \mathrm{mg}$ three times daily). Data are shown for each individual patient, with diagnosis of idiopathic pulmonary fibrosisassociated pulmonary hypertension (PH) (diamonds), non-specific interstitial lung disease-associated PH (squares), sarcoidosis-associated PH (triangles) or scleroderma-associated interstitial lung disease and PH (circles), also indicated.

during the initial 12-week phase of the study and one patient during the long-term extension phase discontinued treatment prematurely because of side-effects considered related to the study drug by both the investigator and the sponsor. The proportions of patients who reported at least one adverse event or serious adverse event are not unusual for a serious condition such as PH-ILD. The absence of a placebo group makes it difficult to distinguish between disease-related and drug-related adverse events. Eight serious adverse events were considered by the investigators potentially related to the study drug and six of these (syncope, respiratory disorder, respiratory failure and three cases of dyspnoea) might be expected in $\mathrm{PH}$ ILD. Two cases of severe pancytopenia were reported. One patient received long-term oral cyclophosphamide; stopping the immunosuppressive treatment resulted in the pancytopenia being no longer clinically relevant. The other patient was treated with azathioprine concomitantly to the study drug. Prior to the study, long-term treatment with azathioprine had been disrupted in this patient due to observed pancytopenia. Both cases recovered without riociguat dose reduction or discontinuation. The majority of the patients who completed the study were uptitrated to the target dose of $2.5 \mathrm{mg}$ three times daily without serious adverse events and no cases of hypotension led to permanent discontinuation of study drug. This trial did not reveal any new safety concerns with riociguat.

In this study riociguat was associated with decreases in PVR and SVR, but the latter effect was somewhat greater, resulting in an increased PVR/SVR ratio. These observations suggest that the predominant effect of riociguat in PH-ILD might have been systemic rather than pulmonary vasodilation. This effect may explain the considerable increase in cardiac output (from 4.4 to $5.5 \mathrm{~L} \cdot \mathrm{min}^{-1}$ between baseline and 12 weeks). It is notable that $\mathrm{mPAP}$ was virtually unchanged overall despite the reduction in
PVR. In some patients, a flow-mediated increase in mPAP, as a consequence of the higher cardiac output, may have offset the effects of pulmonary vasodilation. It is unclear whether the overall workload of the right ventricle was increased or decreased; this question is of importance and deserves further study. The same is true for the left ventricle as patients with chronic lung disease often have impaired left ventricular function [26]. Systemic vasodilation might reduce left ventricular afterload but the increase in cardiac output might add to the left ventricular workload, the net result again being uncertain.

The relatively pronounced systemic vasodilation with riociguat in patients with PH-ILD may explain the different haemodynamic effects seen in the present trial compared with those reported for patients with PAH and CTEPH [24]. Cardiac index was increased to a greater extent in the present study than in patients with PAH $\left(0.4 \mathrm{~L} \cdot \mathrm{min}^{-1} \cdot \mathrm{m}^{-2}\left(\right.\right.$ range, $\left.0.2-0.8 \mathrm{~L} \cdot \mathrm{min}^{-1} \cdot \mathrm{m}^{-2}\right)$ ) or CTEPH $\left(0.4 \mathrm{~L} \cdot \mathrm{min}^{-1} \cdot \mathrm{m}^{-2}\right.$ (range, $\left.0.2-0.8 \mathrm{~L} \cdot \mathrm{min}^{-1} \cdot \mathrm{m}^{-2}\right)$ ). As explained above, a flow-mediated increase in $\mathrm{mPAP}$ as a consequence of the increased cardiac output may explain why the effect on this parameter was variable, with some patients even showing an increase in mPAP. By contrast, in PAH and CTEPH patients, riociguat lowered $\mathrm{mPAP}$ (by $6 \mathrm{mmHg}$ and $4 \mathrm{mmHg}$, respectively) and reduced the PVR/SVR ratio (by $8 \%$ and $5 \%$, respectively). These observations highlight the possibility of different haemodynamic effects of riociguat in different patient populations.

The effects of riociguat on gas exchange were as expected. There was a small decrease in arterial oxygen saturation after 12 weeks. At the same time, $\mathrm{SvO}_{2}$ increased slightly owing to the increased cardiac output. At 12 months $\mathrm{PaO}_{2}, \mathrm{PaCO}_{2}$ and $\mathrm{SaO}_{2}$ showed small changes compared with baseline, but once again, this observation should be viewed with caution because of the small sample sizes.

The positive impact of riociguat on cardiac output did not translate into substantial clinical improvements. There was a slight increase in 6MWD at 12 weeks and a more pronounced increase at 12 months in patients remaining on riociguat over that time, which, given the lack of a control group and the fairly high number of drop-outs, should not be overemphasised, especially as functional class remained unchanged in almost all patients.

The ILD patients selected in the present study were a subgroup that may be considered likely to respond to PH-targeted therapy. The functional impairment of patients with mild-to-moderate pulmonary fibrosis but moderate-to-severe $\mathrm{PH}$ may be linked to ventilatory limitation and, to a greater extent, haemodynamic compromise. Thus, there are several explanations for the lack of a substantial functional improvement in the present study: 1) the rationale may be wrong and these patients are unlikely to benefit functionally from $\mathrm{PH}$-targeted therapy regardless of haemodynamic improvements; 2 ) riociguat may not be the ideal drug for these patients, at least not in the doses administered during this study; 3 ) the study was too small, too heterogeneous and too short to demonstrate a meaningful clinical benefit; and 4) riociguat may only be effective in certain subpopulations. These explanations and views will be explored in further clinical studies.

The present study has several limitations. The patient population was small and heterogeneous, there was no control group, 
there were several drop-outs, and the observation time of the main study was short (12 weeks). Nonetheless, this was a pilot trial primarily designed to assess safety, and it represents the only trial in PH-ILD with invasive haemodynamic assessments at baseline and follow-up. Despite its limitations, the current study highlights the need for a better understanding of the interplay between the haemodynamic, physiological and clinical effects of a drug, and raises important questions about the end-points in future trials in the PH-ILD population. Shortterm changes in haemodynamics or blood gases are not sufficient to predict the effects of treatment on functional capacity or long-term outcomes. Only an adequately powered long-term trial addressing morbidity and mortality end-points will provide the data needed to answer these questions and we should remain reluctant to use $\mathrm{PH}$-targeting drugs in patients with chronic lung disease outside the setting of clinical trials until such data are available.

In conclusion, the results of this pilot trial indicate that riociguat appears to be well tolerated by the majority of patients with PH-ILD. It is associated with a substantial increase in cardiac output and reductions in SVR and PVR, and may have the potential to improve exercise capacity in some patients. Larger controlled studies are warranted to further investigate the safety, impact on gas exchange, dosing and efficacy of riociguat in this patient population. Such studies might also increase our understanding of PH-ILD, a condition which has been inadequately investigated in clinical trials.

\section{SUPPORT STATEMENT}

This study was sponsored by Bayer HealthCare, Berlin, Germany

\section{CLINICAL TRIAL}

This study is registered at www.clinicaltrials.gov with identifier number NCT00694850.

\section{STATEMENT OF INTEREST}

Conflict of interest information can be found alongside the online version of this article at www.erj.ersjournals.com

\section{ACKNOWLEDGEMENTS}

The authors would like to thank the study investigators: Claus Neurohr, Andrea Wälde and Elisabeth Becker (Ludwig Maximilian University of Munich, Munich, Germany), Lars Knudsen (Hannover Medical School, Hannover, Germany) and Gert Hoeffken (University Hospital Carl Gustav Carus, Dresden, Germany). The authors thank Thititat Thanachartwet (Bayer HealthCare, Beijing, China) and Sylvia Nikkho (Bayer Pharma AG, Berlin, Germany) for their support in the data analysis. Editorial assistance was provided by Adelphi Communications (Bollington, UK), supported by Bayer HealthCare, Germany.

\section{REFERENCES}

1 Behr J, Ryu JH. Pulmonary hypertension in interstitial lung disease. Eur Respir J 2008; 31: 1357-1367.

2 Chung F, Dean E. Pathophysiology and cardiorespiratory consequences of interstitial lung disease-review and clinical implications: a special communication. Phys Ther 1989; 69: 956-966.

3 Hoeper MM, Barberà JA, Channick RN, et al. Diagnosis, assessment, and treatment of non-pulmonary arterial hypertension pulmonary hypertension. J Am Coll Cardiol 2009; 54: S85-S96.

4 Shorr AF, Helman DL, Davies DB, et al. Pulmonary hypertension in advanced sarcoidosis: epidemiology and clinical characteristics. Eur Respir J 2005; 25: 783-788.
5 Shorr AF, Wainright JL, Cors CS, et al. Pulmonary hypertension in patients with pulmonary fibrosis awaiting lung transplant. Eur Respir J 2007; 30: 715-721.

6 Nathan SD, Shlobin OA, Ahmad S, et al. Pulmonary hypertension and pulmonary function testing in idiopathic pulmonary fibrosis. Chest 2007; 131: 657-663.

7 Lettieri CJ, Nathan SD, Barnett SD, et al. Prevalence and outcomes of pulmonary arterial hypertension in advanced idiopathic pulmonary fibrosis. Chest 2006; 129: 746-752.

8 Hamada K, Nagai S, Tanaka S, et al. Significance of pulmonary arterial pressure and diffusion capacity of the lung as prognosticator in patients with idiopathic pulmonary fibrosis. Chest 2007; 131: 650-656.

9 Wilkins MR, Wharton J, Grimminger F, et al. Phosphodiesterase inhibitors for the treatment of pulmonary hypertension. Eur Respir J 2008; 32: 198-209.

10 Gomberg-Maitland M, Olschewski H. Prostacyclin therapies for the treatment of pulmonary arterial hypertension. Eur Respir J 2008; 31: 891-901.

11 Dupuis J, Hoeper MM. Endothelin receptor antagonists in pulmonary arterial hypertension. Eur Respir J 2008; 31: 407-415.

12 Collard HR, Anstrom KJ, Schwarz MI, et al. Sildenafil improves walk distance in idiopathic pulmonary fibrosis. Chest 2007; 131: 897-899.

13 Foley RJ, Metersky ML. Successful treatment of sarcoidosisassociated pulmonary hypertension with bosentan. Respiration 2008; 75: 211-214.

14 Ghofrani HA, Wiedemann R, Rose F, et al. Sildenafil for treatment of lung fibrosis and pulmonary hypertension: a randomised controlled trial. Lancet 2002; 360: 895-900.

15 Olschewski H, Ghofrani HA, Walmrath D, et al. Inhaled prostacyclin and iloprost in severe pulmonary hypertension secondary to lung fibrosis. Am J Respir Crit Care Med 1999; 160: 600-607.

16 Zisman DA, Schwarz M, Anstrom KJ, et al. A controlled trial of sildenafil in advanced idiopathic pulmonary fibrosis. N Engl J Med 2010; 363: 620-628.

17 Galiè N, Hoeper MM, Humbert M, et al. Guidelines for the diagnosis and treatment of pulmonary hypertension. Eur Respir J 2009; 34: 1219-1263.

18 Bradley B, Branley HM, Egan JJ, et al. Interstitial lung disease guideline: the British Thoracic Society in collaboration with the Thoracic Society of Australia and New Zealand and the Irish Thoracic Society. Thorax 2008; 63: Suppl. 5, 1-58.

19 Arnold WP, Mittal CK, Katsuki S, et al. Nitric oxide activates guanylate cyclase and increases guanosine $3^{\prime}: 5^{\prime}$-cyclic monophosphate levels in various tissue preparations. Proc Natl Acad Sci USA 1977; 74: 3203-3207.

20 Ignarro LJ, Buga GM, Wood KS, et al. Endothelium-derived relaxing factor produced and released from artery and vein is nitric oxide. Proc Natl Acad Sci USA 1987; 84: 9265-9269.

21 McLaughlin VV, McGoon MD. Pulmonary arterial hypertension. Circulation 2006; 114: 1417-1431.

22 Stasch JP, Pacher P, Evgenov OV. Soluble guanylate cyclase as an emerging therapeutic target in cardiopulmonary disease. Circulation 2011; 123: 2263-2273.

23 Mittendorf J, Weigand S, Alonso-Alija C, et al. Discovery of riociguat (BAY 63-2521): a potent, oral stimulator of soluble guanylate cyclase for the treatment of pulmonary hypertension. ChemMedChem 2009; 4: 853-865.

24 Ghofrani HA, Hoeper MM, Halank M, et al. Riociguat for chronic thromboembolic pulmonary hypertension and pulmonary arterial hypertension: a phase II study. Eur Respir J 2010; 36: 792-799.

25 Grimminger F, Weimann G, Frey R, et al. First acute haemodynamic study of soluble guanylate cyclase stimulator riociguat in pulmonary hypertension. Eur Respir J 2009; 33: 785-792.

26 Barr RG, Bluemke DA, Ahmed FS, et al. Percent emphysema, airflow obstruction, and impaired left ventricular filling. $N$ Engl J Med 2010; 362: 217-227. 